\title{
Prognostic prediction of glioblastoma by quantitative assessment of the methylation status of the entire MGMT promoter region
}

Manabu Kanemoto ${ }^{1,2}$, Mitsuaki Shirahata ${ }^{3}$, Akiyo Nakauma ${ }^{1}$, Katsumi Nakanishi ${ }^{1}$, Kazuya Taniguchi ${ }^{1}$, Yoji Kukita $^{1}$, Yoshiki Arakawa², Susumu Miyamoto ${ }^{2}$ and Kikuya Kato ${ }^{1 *}$

\begin{abstract}
Background: O6-methylguanine-DNA methyltransferase (MGMT) promoter methylation is reported to be a prognostic and predictive factor of alkylating chemotherapy for glioblastoma patients. Methylation specific PCR (MSP) has been most commonly used when the methylation status of MGMT is assessed. However, technical obstacles have hampered the implementation of MSP-based diagnostic tests. We quantitatively analyzed the methylation status of the entire MGMT promoter region and applied this information for prognostic prediction using sequencing technology.

Methods: Between 1998 and 2012, the genomic DNA of 85 tumor samples from newly diagnosed glioblastoma patients was subjected to bisulfite treatment and subdivided into a training set, consisting of fifty-three samples, and a test set, consisting of thirty-two samples. The training set was analyzed by deep Sanger sequencing with a sequencing coverage of up to 96 clones per sample. This analysis quantitatively revealed the degree of methylation of each cytidine phosphate guanosine $(\mathrm{CpG})$ site. Based on these data, we constructed a prognostic prediction system for glioblastoma patients using a supervised learning method. We then validated this prediction system by deep sequencing with a next-generation sequencer using a test set of 32 samples.
\end{abstract}

Results: The methylation status of the MGMT promoter was correlated with progression-free survival (PFS) in our patient population in the training set. The degree of correlation differed among the CpG sites. Using the data from the top twenty CpG sites, we constructed a prediction system for overall survival (OS) and PFS. The system successfully classified patients into good and poor prognosis groups in both the training set (OS, $p=0.0381 ; \mathrm{PFS}, \mathrm{p}=0.00122)$ and the test set (OS, $p=0.0476 ; P F S, p=0.0376)$. Conventional MSP could not predict the prognosis in either of our sets. (training set: OS; $p=0.993$ PFS; $p=0.113$, test set: OS; $p=0.326$ PFS; $p=0.342$ ).

Conclusions: The prognostic ability of our prediction system using sequencing data was better than that of methylation-specific PCR (MSP). Advances in sequencing technologies will make this approach a plausible option for diagnoses based on MGMT promotor methylation.

Keywords: Glioma, O6-methylguanine-DNA methyltransferase, Methylation, Bisulfite genome sequencing, Next-generation sequencing

\footnotetext{
* Correspondence: katou-ki@mc.pref.osaka.jp

${ }^{1}$ Research Institute, Osaka Medical Center for Cancer and Cardiovascular

Diseases, 1-3-3 Nakamichi, Higashinari-ku, Osaka, Japan

Full list of author information is available at the end of the article
} 


\section{Background}

A glioblastoma (GB) is a malignant brain tumor with a poor prognosis; the median survival time of GB patients is less than 2 years [1]. The current standard of care for GB patients is maximum surgical resection combined with radiation and concomitant adjuvant temozolomide (TMZ) therapy [2]. The long-term results of the EORTCNCIC CE.3 trial revealed that the 5-year survival of GB patients approaches $10 \%$, despite the largely poor prognosis [3]. Although novel drugs, such as molecular-targeted drugs, have been developed, their survival benefit has not been confirmed, and these molecular targeted drugs are known to carry risks of specific adverse events [4-6]. Accordingly, it is important to identify patients who may respond to conventional chemo-radiation therapy as part of future personalized care. Although nitrosoureas were commonly used for chemotherapy, TMZ is now used for first-line therapy. These drugs are alkylating agents that add an alkyl group to the O6 position of guanine, damaging the genomic DNA of cancer cells. O6methylguanine-DNA methyltransferase (MGMT) removes alkyl groups from the $\mathrm{O} 6$ position of guanine and plays an important role in DNA repair [7-10]. Therefore, MGMT expression is associated with resistance to chemotherapeutic alkylating agents. The expression of $M G M T$ is controlled by epigenetic gene silencing [11-13]. The methylation of the MGMT promoter is associated with sensitivity to alkylating chemotherapy drugs and is recognized as a prognostic factor for GB patients [14-18].

In recent years, TMZ monotherapy has been attempted for elderly GB or low-grade glioma patients, and an association between the treatment response and the MGMT methylation status has been examined $[19,20]$. These studies demonstrated that the methylation status of MGMT is a strong predictive factor of TMZ monotherapy outcomes in elderly GB patients, and the clinical utility of the MGMT methylation status is increasing [21,22].

Even with this accumulating clinical evidence, the implementation of diagnostic tests examining the methylation status of the MGMT promoter has been difficult. PCR-based techniques, such as methylation-specific PCR (MSP) and quantitative MSP, are the most popular methods of assessment [23,24]. These techniques detect methylation sequences by sequence-specific binding of primers, which is an indirect method and only detects a limited number of methylation sites. DNA sequencing (i.e., bisulfite genomic sequencing) provides more direct information on methylation status. In this context, pyrosequencing is considered a good alternative. However, the target methylation sites of pyrosequencing are also limited [25,26]. The MGMT promoter region spans more than one thousand base pairs and contains approximately one hundred potential methylation sites. To assess the methylation status of the MGMT promoter, it would be preferable to assess information from all methylation sites and select important CpG sites with survival analysis.

In this report, we performed deep sequencing of the MGMT promoter region after bisulfite treatment to clarify the global methylation status of the region. Because the methylation status is not uniform in glioma tissue, it is important to characterize the intratumor heterogeneity of MGMT promoter methylation. An analysis of survival data assessed the correlation between each CpG site and the malignancy of the glioblastoma. Based on this correlation, we built a classifier to predict the malignancy of GB using deep sequencing with a nextgeneration sequencer.

\section{Methods}

\section{Patient characteristics}

We obtained 85 GB specimens from patients who underwent surgical resection at Kyoto University Hospital and related regional hospitals between 1998 and 2012. The majority of the patients were recruited for a phase II clinical trial [27], and their tissues were used for studies on gene expression profiling $[28,29]$. Histological diagnoses were established by the Kyoto University Pathology Unit according to the criteria established by the World Health Organization. The protocol was approved by the institutional review board of Kyoto University, and written informed consent was obtained from each of the patients. All tumor specimens were immediately snap frozen upon surgical resection and stored at $-80^{\circ} \mathrm{C}$ until use. Tumor specimens containing $20 \%$ or more non-tumor tissue or necrotic areas were excluded from further analysis. The preoperative Karnofsky performance status score of each patient was at least 50 for each case. All patients received radiation therapy with and without alkylating chemotherapy postoperatively. The patient characteristics are shown in Table 1. We divided the data matrix into two data sets: one set consisted of 53 patients and was designated as the training set, and the other set contained 32 patients and was designated as the test set.

\section{DNA extraction and bisulfite treatment}

Genomic DNA was extracted with the QIAamp DNA Mini Kit (Qiagen) according to the manufacturer's instructions. One nanogram of genomic DNA was subjected to bisulfite treatment using the MethylEasy DNA Bisulfite Modification Kit (Takara) in accordance with the manufacturer's instructions. We determined the quality of bisulfite-treated genomic DNA by real-time PCR of the actin gene as previously described [30]. The outline of the procedure is schematically shown in Additional file 1: Figure S1. 
Table 1 Patients' clinical characteristics

\begin{tabular}{cccc}
\hline Sample & & 85 & \\
Age & Female & $6-88$ & Median: 60 \\
Gender & Male & 46 & \\
Removal & Biopsy & 1 & \\
& Partial & 29 & \\
Subtotal & 28 & \\
Total & 20 & \\
Post operative therapy & Unknown & 8 & \\
& VAC-feron & 57 & \\
& Temozolomide & 14 & \\
& Other ACNU regimen & 4 & \\
& Radiation alone & 7 & \\
& Other & 3 & \\
Overall survival (months) & $3-96$ & Median: 12 \\
Progression free survival (months) & $1-96$ & Median: 6 \\
\hline
\end{tabular}

\section{Methylation-specific PCR (MSP)}

Conventional MSP was performed as previously described [31]. PCR was performed using AmpliTaq Gold polymerase and the GeneAmp PCR system 9700 (Applied Biosystems). The sequences of the primer pairs were 5' -TTTGTGTTTTGATGTTTGTAGGTTTTTGT3' and 5'-AACTCCACACTCTTCCAAAAACAAAACA3' for unmethylated MGMT (fragment size: $93 \mathrm{bp}$ ) and 5' - TTTCGACGTTCGTAGGTTTTCGC -3' and 5'-GCA CTCTTCCGAAAACGAAACG-3' for methylated MGMT (fragment size: $81 \mathrm{bp}$ ). These sequences and the PCR primer sequences used in the further analysis were constructed according to the MGMT promoter sequence (http://www.ncbi.nlm.nih.gov/nuccore/X61657.1). After an initial incubation at $95^{\circ} \mathrm{C}$ for $12 \mathrm{~min}$, PCR amplification was performed with 40 cycles of $95^{\circ} \mathrm{C}$ for $15 \mathrm{sec}, 59^{\circ} \mathrm{C}$ for $30 \mathrm{sec}$, and $72^{\circ} \mathrm{C}$ for $30 \mathrm{sec}$, followed by a 4-min final extension. The PCR products were electrophoresed on $2 \%$ agarose gels and were classified as methylated if a band with the PCR product was visualized using the methylated primer. The experiments were performed twice to confirm the reproducibility of the results. There were no discrepancies between duplicate reactions.

\section{Quantitative bisulfite genome sequencing (qBGS) of the training set}

For qBGS, the MGMT promoter region was amplified by nested PCR. The sequences of the first-round PCR primers were $5^{\prime}$-TGGTAAATTAAGGTATAGAGTTTT AGG-3' and 5'-GGTTAGGTGTTAGTGATGTT-3'. The PCR protocol was optimized for bisulfite-treated genomic DNA; each $10-\mu \mathrm{l}$ reaction mixture of the modified protocol contained $2.5 \mathrm{mM} \mathrm{MgCl}_{2}, 3 \%$ DMSO, 20 ng bisulfite- treated genomic DNA, and $1 \mu \mathrm{l}$ of AmpliTaq Gold. After an initial incubation at $95^{\circ} \mathrm{C}$ for $12 \mathrm{~min}$, PCR amplification was performed using 30 cycles of $95^{\circ} \mathrm{C}$ for $15 \mathrm{sec}, 54^{\circ} \mathrm{C}$ for $30 \mathrm{sec}$ and $72^{\circ} \mathrm{C}$ for $1 \mathrm{~min}$, followed by a 4-min final extension. A 1- $\mu$ l aliquot of the first-round PCR product was used as the template of the second-round PCR reaction. The sequences of the second-round PCR primers were $5^{\prime}$ TGGTAAATTAAGGTATAGAGTTTTAGG-3' and 5' -TT GGATTAGGTTTTTGGGGTT-3' (fragment size: 662 bp). The genomic position is chr 10: 131,155,100-131,155,761. The second-round PCR was performed using KOD-plus DNA polymerase (TOYOBO) according to the manufacturer's instructions with $1.5 \mathrm{mM} \mathrm{MgSO}_{4}$ and 3\% DMSO. After an initial incubation at $95^{\circ} \mathrm{C}$ for $2 \mathrm{~min}$, PCR amplification was performed with 30 cycles of $94^{\circ} \mathrm{C}$ for $15 \mathrm{sec}$, $58^{\circ} \mathrm{C}$ for $30 \mathrm{sec}$, and $68^{\circ} \mathrm{C}$ for $1 \mathrm{~min}$. The PCR products were purified using the MinElute PCR Purification Kit (QIAGEN) and ligated into the pCR-Blunt plasmid using the Zero Blunt PCR Cloning Kit (Invitrogen) and a DNA ligation kit (Takara). MAX Efficiency DH5 Competent Cells (Invitrogen) were used for transformations. A total of 96 colonies of each sample were subjected to bisulfite sequencing using a 3730xl DNA Analyzer (Applied Biosystems). The methylation status was analyzed with QUMA web tools (http://quma.cdb.riken.jp/).

\section{qBGS for the test set}

For the test set, we used next-generation sequencing (MiSeq, Illumina) instead of Sanger sequencing. The target sequence was amplified by nested PCR. PCR amplification was performed using 40 cycles of $94^{\circ} \mathrm{C}$ for $30 \mathrm{sec}$, $54^{\circ} \mathrm{C}$ for $30 \mathrm{sec}$, and $72^{\circ} \mathrm{C}$ for $45 \mathrm{~min}$, followed by a 4-min final extension. The sequences of the first-round PCR primers were 5'-GGATATGTTGGGATAGTT-3' and $5^{\prime}$-CCAAAAACCCCAAACCC-3' [26]. The sequences of the second-round PCR primers were $5^{\prime}$ GGATATGTTGGGATAGTT-3' and 5' - AAATAAATAA AAATCAAAAC-3' (fragment size: $216 \mathrm{bp}$ ). The annealing temperature was $48^{\circ} \mathrm{C}$ in the second-round PCR. The PCR product was attached with an adapter for MiSeq plus, consisting of an eight- or six-base index. The pooled PCR library of the test set samples was sequenced by paired-end sequencing with a MiSeq sequencer. Pairedend reads were aligned to a C-to- $\mathrm{T}$ converted reference sequence of the MGMT promoter region using BWA [32]. We used SAMtools to obtain the per-base coverage (pileup files) and counted non-bisulfite converted sites [33].

\section{Statistical analysis}

Statistical analyses were performed using the free statistics software R (http://www.r-project.org/). Overall survival (OS) and progression-free survival (PFS) were defined as the period from surgery to death and from surgery to radiological detection of tumor progression, 
respectively. Tumor progression was diagnosed based on the criteria of the Brain Tumor Registry committee (Japan), which includes: a 25\% increase in tumor size, the appearance of new lesions, or the obvious deterioration of the patient due to a mass effect or perifocal edema (in Table 1).

\section{Results}

Quantitative bisulfite genome sequencing of the training set

Bisulfite sequencing was performed to fully analyze the methylation status of the MGMT promoter region. Due to intratumor heterogeneity, the methylation status of individual cells is not identical, even within a single glioma tissue. To clarify this heterogeneity, we performed quantitative bisulfite sequencing and obtained data from 25 to 81 molecules (median, 51) from each sample. This approach is referred to as quantitative bisulfite genome sequencing (qBGS). The 662-bp fragment subjected to qBGS contained $78 \mathrm{CpG}$ sites. One CpG site that is not located within the CpG island of the MGMT promoter region was excluded from further analysis. The methylation proportion at each $\mathrm{CpG}$ site was calculated as the fraction of clones with a methylated $\mathrm{C}$ at that site in all sequenced clones. The methylation status of the MGMT promoter region was then described as a data point in a 77-dimensional space constructed from the methylation proportions of the $77 \mathrm{CpG}$ sites. We performed a hierarchical cluster analysis with the Ward method using the raw methylation proportion without any standardization to obtain a general view of the global methylation features of the MGMT promoter region. The cases were grouped into four clusters (Figure 1A). These clusters were correlated with the degree of methylation. The column bars below the clustering indicate the MSP results for 53 samples. Typical examples of qBGS results are shown in Figure 2. The samples in cluster 1 were strongly methylated, the samples in cluster 2 were moderately methylated, the samples in cluster 3 were slightly methylated, and the samples in cluster 4 were almost

A

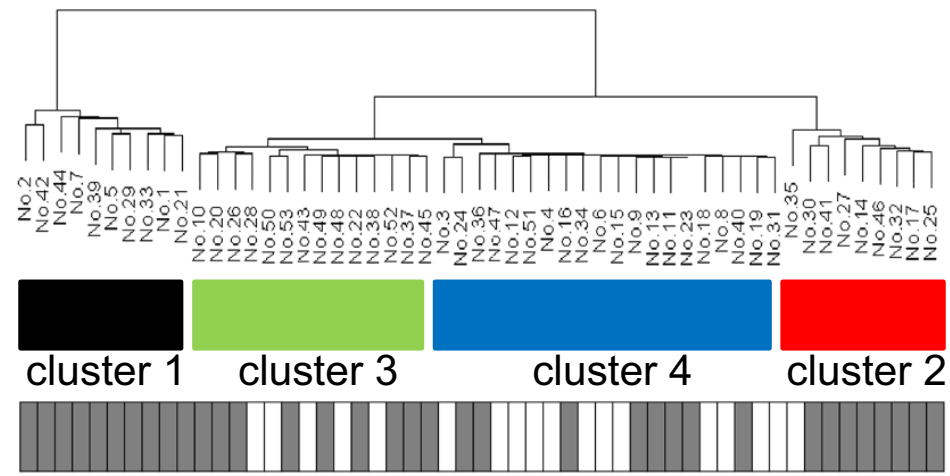

B

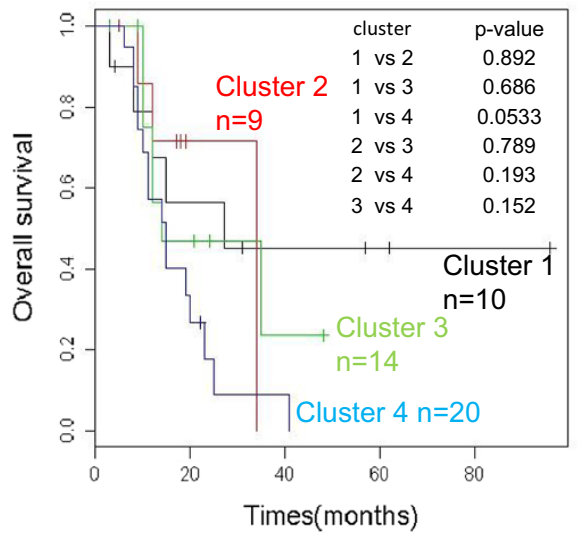

C

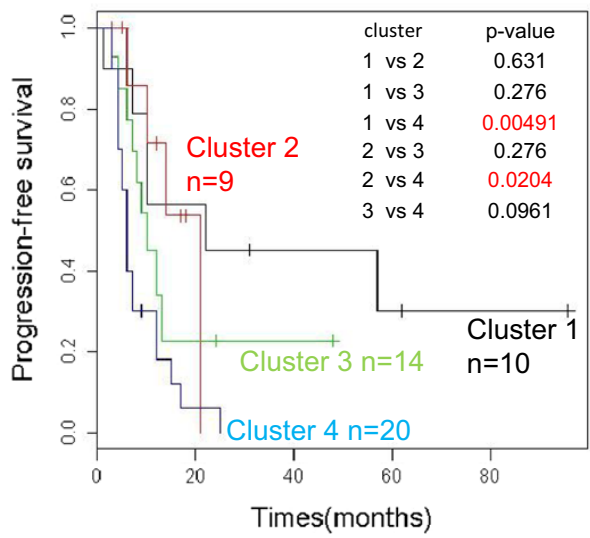

Figure 1 Clustering of the training set and survival analysis. Unsupervised analysis based on the MGMT methylation patterns. (A) A hierarchical cluster analysis of the methylation of the MGMT promoter in 53 samples. Cluster 1 (Black), strongly methylated samples; cluster 2 (red), moderately methylated; cluster 3 (green), slightly methylated; cluster 4 (blue), mostly unmethylated. The columns below the clustering show the results obtained using MSP. The gray column indicates methylated, and the white column is unmethylated samples. (B, $\mathbf{C})$ Survival analysis was performed between all combinations of the four cluster subgroups. For PFS, the analysis showed statistically significant differences between cluster 1 and cluster $4(p=0.00491)$ and between cluster 2 and cluster $4(p=0.0204)$. For OS, there was no statistically significant difference between any combination of the four clusters, but there was a trend toward a difference between cluster 1 and cluster 4 ( $p=0.0533$ ). 


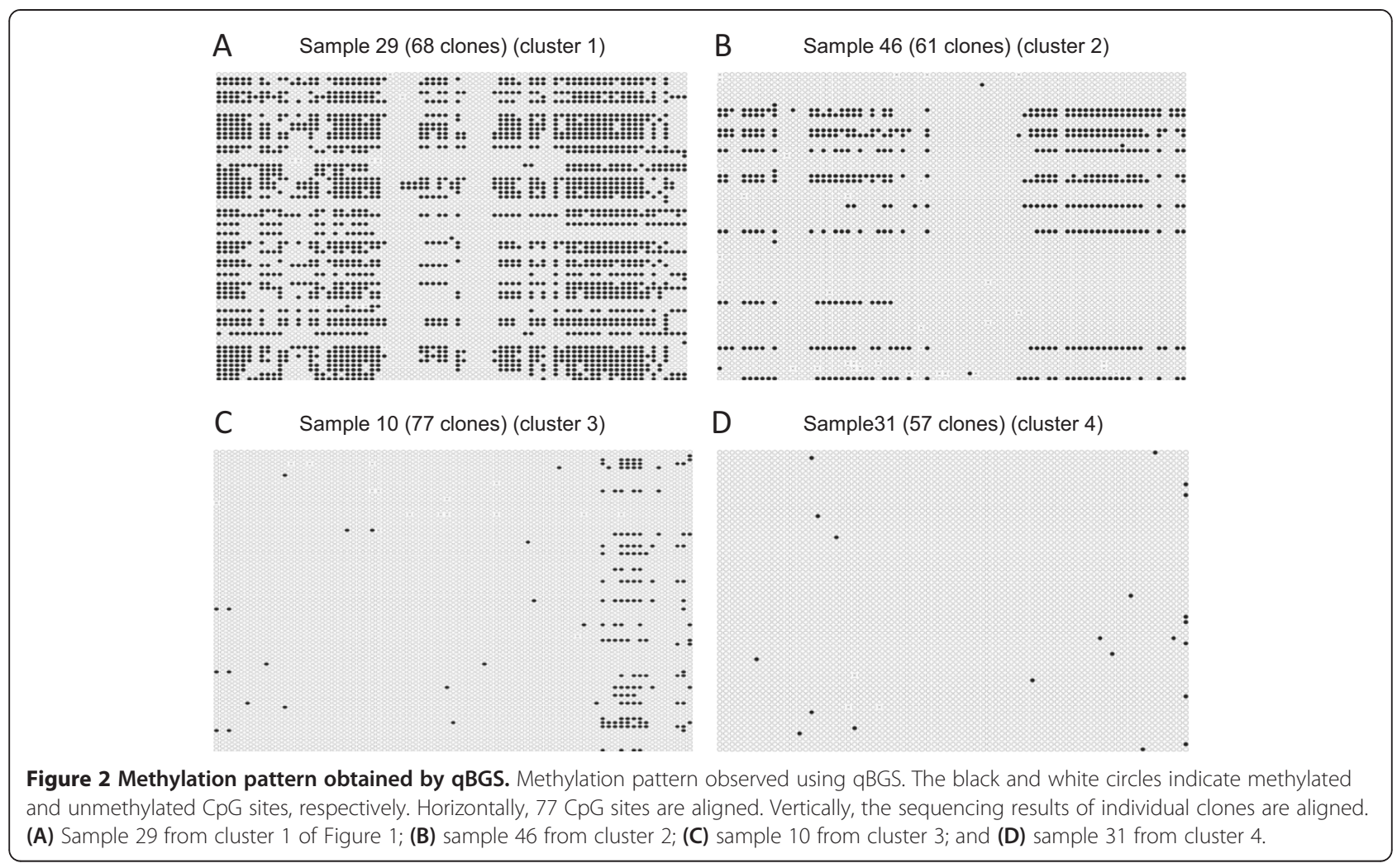

unmethylated. There was a trend toward a prognostic difference for OS between cluster 1 and cluster $4(\mathrm{p}=$ 0.0533) (Figure 1B). Statistically significant associations with PFS were observed between clusters 1 and $4(\mathrm{p}=$ $0.00491)$ and between clusters 2 and $4(\mathrm{p}=0.0204)$ (Figure 1C). Several cases that were judged to be methylated (i.e., to have a good prognosis) by MSP belonged to clusters 3 and 4 (Figure 1A). For example, samples 13 and 16 belonged to cluster 4; both showed four months of PFS and were described as poor prognosis [2], but were judged to be methylated and to have a good prognosis by MSP.

To demonstrate an overview of the methylation status of the MGMT promoter region, the averages of the methylation proportions of the CpG sites are shown in Figure 3. The promoter sequence may be divided into three segments according to the methylation proportions. The methylation level of the CpG sites in the middle segment, from CpG28 to CpG50, was lower than that of the other segments (Figure 3). This area is located just upstream of the transcription start site. We performed univariate Cox proportional hazard analysis of PFS to identify prognostically important CpG sites using the methylation proportion as a continuous variable. Based on an analysis using the 53 training samples, the log-rank $\mathrm{p}$ values of $20 \mathrm{CpG}$ sites were less than 0.05. These 20 selected CpG sites were CpG63 ( $p=0.0056)$, CpG64 ( $\mathrm{p}=0.0088)$, CpG77 ( $\mathrm{p}=0.010)$, CpG62 ( $\mathrm{p}=0.012)$,
CpG56 ( $\mathrm{p}=0.012)$, CpG68 ( $\mathrm{p}=0.014)$, CpG11 $(\mathrm{p}=0.023)$, CpG65 (p=0.025), CpG66 (p=0.025), CpG59 (p=0.027), CpG8 (p=0.028), CpG60 (p=0.028), CpG10 ( $\mathrm{p}=0.030)$, CpG7 $(\mathrm{p}=0.034)$, CpG5 $(\mathrm{p}=0.034)$, CpG61 $\quad(\mathrm{p}=0.035)$, CpG54 ( $\mathrm{p}=0.038)$, CpG9 ( $\mathrm{p}=0.038)$, CpG47 $(\mathrm{p}=0.047)$, and CpG67 $(\mathrm{p}=0.048)$. Almost all of the selected sites were located at positions from CpG5 to CpG11 or from CpG54 to CpG68 (black columns in Figure 3). However, only five $\mathrm{CpG}$ sites were selected for OS under the same condition: CpG8 ( $\mathrm{p}=0.039), \mathrm{CpG} 28(\mathrm{p}=0.041)$, CpG56 $(\mathrm{p}=0.041), \quad$ CpG5 $(\mathrm{p}=0.044)$, and CpG45 $(\mathrm{p}=0.049)$ (gray columns in Figure 3). Three CpG sites, CpG5, CpG8, and CpG56, showed a correlation with OS and PFS. All of the results of univariate Cox analysis are supplied in Additional file 2 (PFS) and Additional file 3 (OS). Shah et al. reported a similar comprehensive methylation analysis [34]. Their numbering scheme of CpG sites corresponds to the addition of twenty to our numbering scheme of sites.

\section{Diagnostic system for prognosis prediction using quantitative methylation data}

As described above, the prognostic significance of each CpG site is limited, and it would be more effective to combine the information from multiple CpG sites. One approach is an unsupervised analysis, including a cluster analysis, shown above. However, to construct a diagnostic system, supervised learning is more appropriate. 


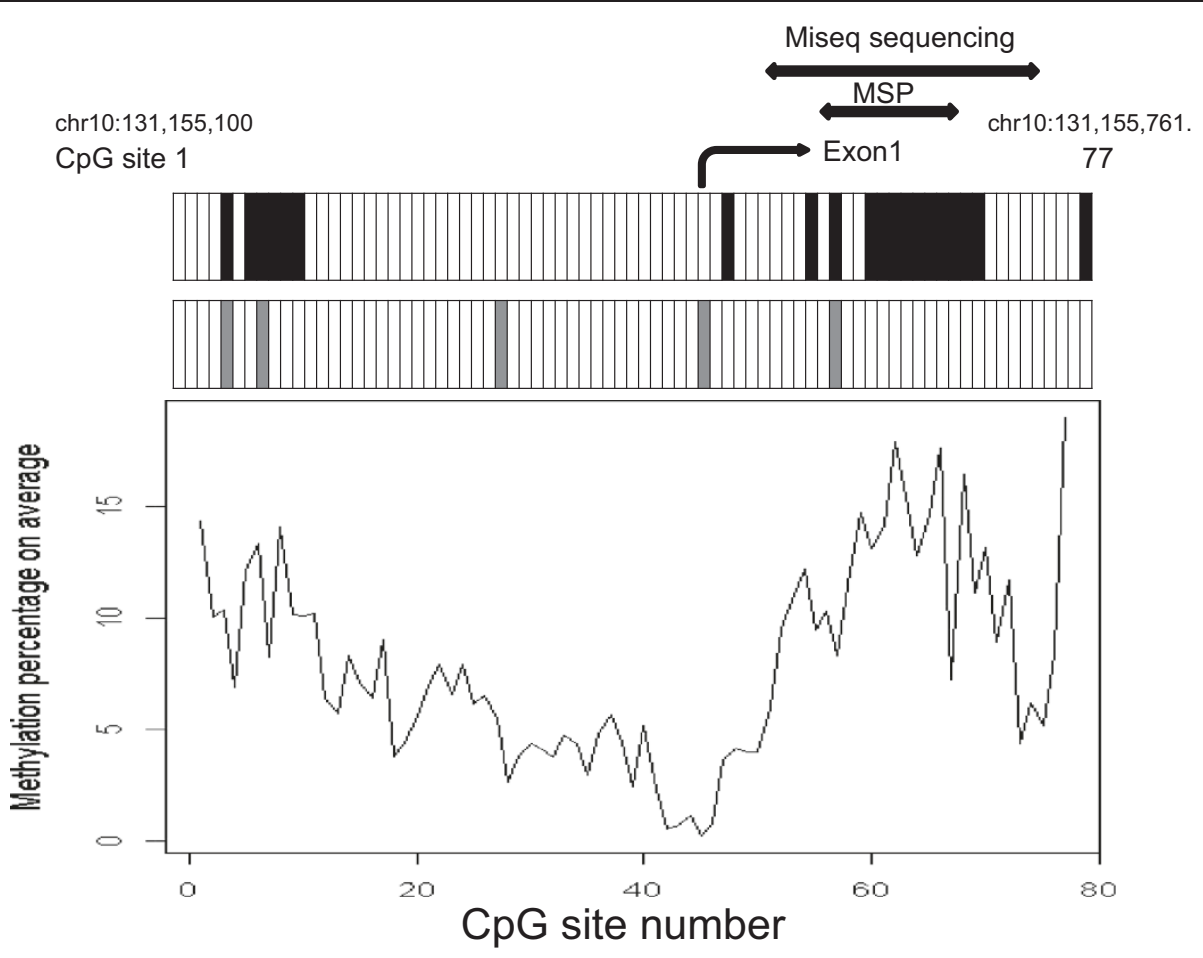

Figure 3 Proportion of methylation status and survival analysis at each CpG site. Average of the methylation percentage of CpG sites. The black and gray columns in the top panel indicate CpG sites with correlations with PFS and OS, respectively, that exceed the threshold $(p<0.05)$.

Here, based on the correlation between OS or PFS and the methylation status of the MGMT promoter region, we constructed a diagnostic system to predict the therapeutic outcomes of GB patients based on the methylation proportion of CpG51 - CpG74. Because we intended to use a next-generation sequencer for the validation study, we selected the CpG sites to be examined based on the read length restriction of the sequencer. This diagnostic score was denoted as the M-score (methylation score) and is defined as a weighted sum of the methylation proportion as follows:

$$
M_{-}(\text {methylation }) \_ \text {score }=-\sum_{i} A_{i} X_{i}
$$

where ' $A_{i}$ ' is a regression coefficient deduced by univariate Cox analysis of PFS at CpG site $i$ and ' $X_{i}^{\prime}$ ' is the methylation proportion at $\mathrm{CPG}$ site $i$. As described above, a correlation between OS and the methylation status was not clear in our patient population. We therefore used the same M-score calculation formula for OS as well. First, the performance of the M-score diagnostic system was evaluated by leave-one-out-cross-validation (LOOCV) using the 53 training samples. The 53 samples were divided into groups consisting of one and 52 samples, and ' $A i$ ' was calculated by univariate Cox analysis using the data for the remaining 52 samples. The threshold was selected from M-scores of the 52 samples so that the log-rank p value of the Kaplan-Meier analysis for the two divided groups was minimized. In cases of multiple $\mathrm{M}$-scores with the same minimum $\mathrm{p}$ value, the median was selected as the threshold. Next, the M-score of the one sample was calculated using parameters deduced from the 52 samples, and the sample was classified into either the good or poor prognosis group using the threshold. This process was repeated until all samples were tested. The LOOCV procedure is schematically shown in Additional file 1: Figure S2. The results of the LOOCV procedure are shown in Figure 4A and B; this approach demonstrated excellent prognostic ability with OS and PFS (OS, $\mathrm{p}=0.0381$; PFS, $\mathrm{p}=0.00122$ ). Thus, the diagnostic accuracy of our system is better than that of the MSP-based approach (Figure 4C, D) (OS, $\mathrm{p}=0.993 ;$ PFS, $\mathrm{p}=0.113$ ).

\section{Validation of the diagnostic system using next-generation sequencing}

For validation of the test set, the parameters $(A i)$ were calculated using all 53 samples in the training set, and the threshold was set at 2.2, the average of the thresholds of the $53 \mathrm{LOOCV}$ processes.

For the 32 test set samples, we performed qBGS with a next-generation sequencer, MiSeq, to examine the potential future applications of this approach. We also 


\section{Training set}
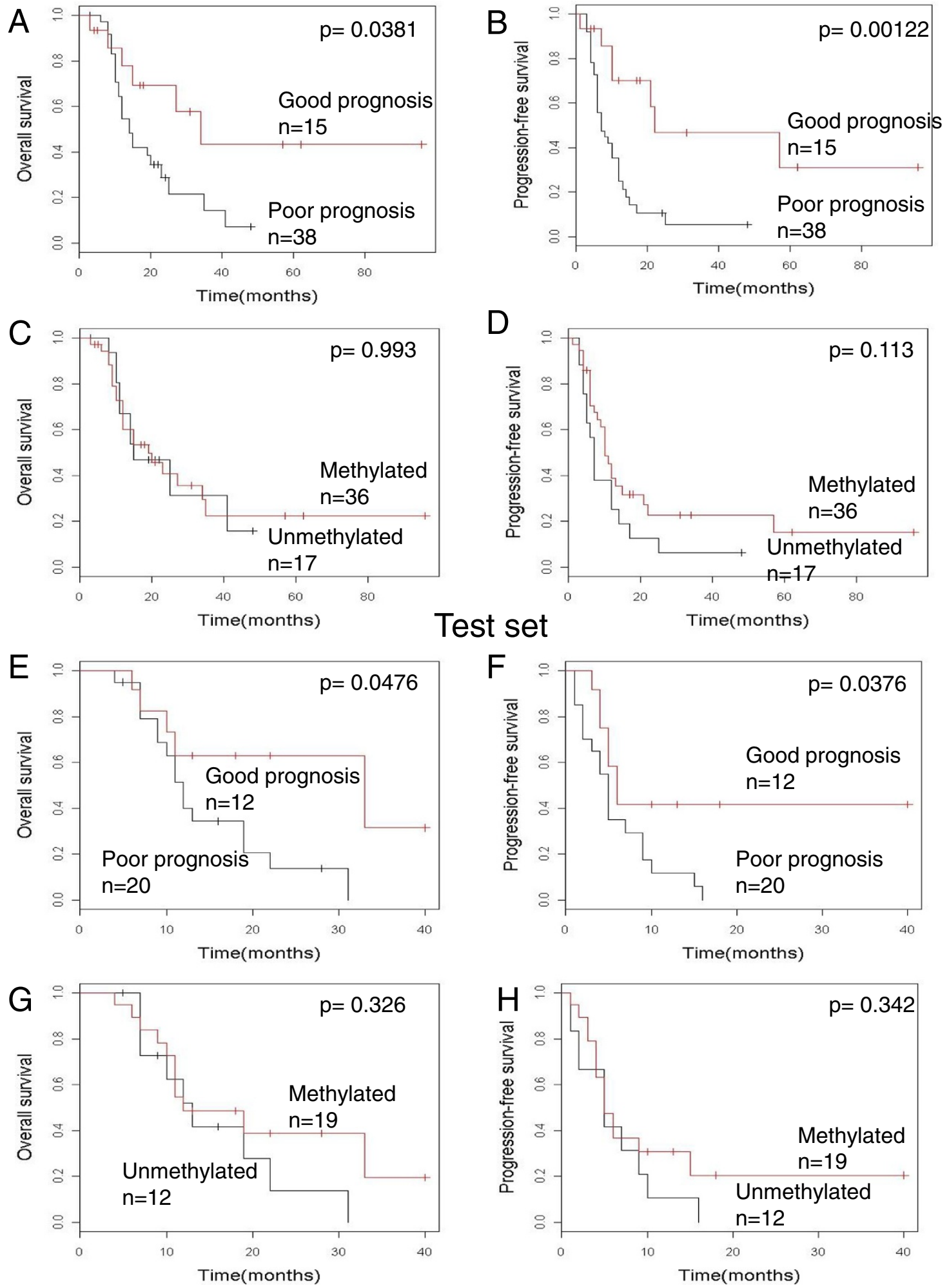

Figure 4 (See legend on next page.) 
(See figure on previous page.)

Figure 4 Survival analysis of the training set by M-score and MSP. In each panel, the red line indicates either a good prognosis (M-score) or the methylated (MSP) group. The black line indicates either a poor prognosis (M-score) or the unmethylated (MSP) group. (A) training set, M-score, OS. (B) training set, M-score, PFS. (C) training set, MSP, OS. (D) training set, MSP, PFS. (E) test set, M-score, OS. (F) test set, M-score, PFS. (G) test set, MSP, OS. (H) test set, MSP, PFS.

performed MSP in all cases except one, due to the loss of genomic DNA. The mean depth of MiSeq sequencing was 80,817 reads. The methylation proportion of each CpG site was obtained, M-scores were calculated, and the test set samples were classified using the threshold listed above. Survival analysis indicated a statistically significant difference between the two groups with respect to PFS $(\mathrm{p}=0.0376)$ and $\mathrm{OS}(\mathrm{p}=0.0476)$ (Figure 4E, F). There was no statistically significant difference between the two groups by classification with MSP (OS, $\mathrm{p}=0.326$; PFS, $\mathrm{p}=0.342$ ) (Figure 4G, H).

For potential future applications of this technique, we designed PCR primers that amplify the same region from FFPE samples. The method and results are shown in Additional file 4.

\section{Multivariate Cox regression analysis}

We performed Cox regression analysis to evaluate clinical parameters, such as age (above or below 60), gender, the extent of resection, post-operative chemotherapy (VAC-feron or TMZ), and the methylation status by the M-score sequencing method as predictors of OS and PFS in the GB patients in the test set. The variables with a $\mathrm{p}$ value $<0.2$ were analyzed with a backward stepwise Multivariate Cox proportional hazard model. For OS, the best predictor was the M-score $(\mathrm{p}=0.0585)$ (Hazard Ratio, 0.3558), and the next best prognostic factor was the extent of surgical resection $(\mathrm{p}=0.0739)$ (Hazard Ratio, 0.5996). The M-score was found to be the best predictor of PFS ( $p=0.0247$; Hazard Ratio, 0.334).

\section{Discussion}

In this report, we characterized the methylation status of the entire MGMT promoter region using deep sequencing. The methylation status of each CpG site was quantitatively evaluated by sequencing multiple clones. Based on these results, we constructed a prognosis predictor that incorporates the methylation status of multiple CpG sites using supervised learning. The construction of a classifier using supervised learning is popular in the field of gene expression profiling, and we demonstrated here that the same approach is effective for the prediction of methylation status.

In our patient population, the correlation of the methylation status with OS was less clear than that with PFS. This is most likely due to variation of the therapy used after the first line therapy. The majority of our patients received repeated surgical resections, second line chemotherapy or additional radiotherapy. For multivariate analysis, age was not a prognosis factor, unlike in the past reports. We also performed surgical medical treatment with methylation-positive elderly patients. In particular, repeated surgery was likely to prolong the survival time of the glioblastoma patients with a poor prognosis.

MSP is the most widely used assay for methylation. However, MSP can only detect the CpG sites in the primer region; the methylation status of other $\mathrm{CpG}$ sites has no effect on the amplification. In a prior study, only $12.5 \%$ of the results obtained from two MSP experiments matched when the forward and reverse primers were different [35]. In addition, there is no established method to confirm the quality of bisulfite-converted genomic DNA. We assessed the quality using the $\mathrm{Ct}$ value of actin in real-time PCR. Approximately 64\% of our glioma samples were methylation-positive with MSP. The positive rate was higher than that in other studies with some exceptions [36,37]. We excluded samples damaged by bisulfite treatment in the actin-based confirmation system, and this process may have increased the positive rate. This discrepancy in MSP results, which is most likely a false positive, might be influenced by the $\mathrm{T}$ genotype of the $M G M T \mathrm{C}>\mathrm{T}$ (rs16906252) enhancer single-nucleotide polymorphism (SNP), which was reported by McDonald et al. [38] to interact with MGMT promotor methylation. Vlassenbroeck et al. also evaluated the results of qMSP based on the copy number of actin using real-time PCR [39]. It is often difficult to set a threshold for agarose gel patterns of MSP. This problem has been overcome by quantitative MSP [40,41]. Quantitative MSP was applied in two recent phase 3 trials of glioma [21,22]. However, the problem of limited coverage of CpG sites by MSP remains in need of technical improvements.

As discussed above, bisulfite sequencing can cover all CpG sites. In this context, pyrosequencing is considered to cover more CpG sites than MSP [26]. The methylation proportions can be semi-quantitatively deduced from the peak height of each incorporated nucleotide. The main disadvantage of pyrosequencing is its short read length $[25,26]$. qBGS using Sanger sequencing is not subject to this limitation, and its moderate read depth provides more accurate quantitative information. Because deep sequencing with the Sanger method is laborious, the use of next-generation sequencing may make this approach more comparable to pyrosequencing. 
The major shortcoming of qBGS and pyrosequencing is the absence of a consensus regarding the data handling of multidimensional quantitative data. Dunn et al. and Motomura et al. used the average of the methylation proportion of multiple CpG sites (CpG51 - CpG62, Dunn et al.; CpG2 - CpG16, Motomura et al.) [42,43]. Karayan-Tapon et al. used the methylation proportion of five $\mathrm{CpG}$ sites (CpG 53-57) and grouped patients using the median value of the methylation proportion as the threshold [25]. We developed the M-score diagnostic system using the analysis method of gene expression profiling and calculated the optimized threshold by LOOCV. The M-score is the weighted sum of the methylation proportions of multiple $\mathrm{CpG}$ sites, which maximizes the correlation with the survival time. Our approach is more advanced than a simple summation of the population of methylated sites, and adding data from a larger patient population will improve the performance of the predictor. Bady et al. examined the quantitative value of $18 \mathrm{CpG}$ sites in the MGMT promoter area using the Infinium methylation BeadChip and revealed two distinct CpG sites (CpG10 and CpG68). They converted multidimensional data to one methylation probability score using the inverse logit function. The classifier was validated with an external data set [44]. Both studies indicate a new direction for MGMT methylation assays based on evaluation of multiple CpG sites.

Shah et al. also quantitatively evaluated the methylation of the MGMT promoter [34]. Although the number of sequenced clones in that study was far less than that of our study (median of 10 clones), their results were similar to our results; the CpG sites located downstream of the transcription start site were often correlated with PFS. This prior study indicates that our observations are likely to be universal, and suggests that our prognosis predictor may be applicable to other patient populations.

The identification of biomarkers of gliomas has been an active area of research in recent years. It is well known that $I D H$ mutations are a strong prognostic factor [45]. IDH mutations are associated with a hypermethylation phenotype [46], suggesting that the methylation of the MGMT promoter is one part of a genome-wide methylation profile [47]. Based on qBGS analysis, we identified different extents of methylation of CpG sites in the MGMT promoter region.

Recently, the methylation status of MGMT has become a focal point in the management of elderly GB patients. Two MGMT methylation analyses using samples from large phase 3 trials with elderly GB patients demonstrated that TMZ monotherapy was superior to conventional radiation therapy for the management of MGMT-methylated GB patients. Conversely, TMZ monotherapy was inferior to radiation therapy in GB cases with unmethylated MGMT [21,22]. These results indicate that the MGMT methylation status is a strong predictive factor for the efficacy of TMZ monotherapy in elderly GB patients and that evaluating MGMT methylation status is necessary for the management of these patients. The relationship between the efficacy of TMZ monotherapy and qBGS-based methylation analysis of the MGMT promoter in elderly GB merits further investigation.

In addition to its application for elderly patients, TMZ monotherapy has been utilized for low-grade glioma patients $[20,48]$. In this group, the co-deletion of $1 \mathrm{p} 19 \mathrm{q}$ and $I D H$ mutations were molecular prognostic factors. Given the findings in elderly GB patients, the methylation status of the MGMT promoter may also predict the outcomes of low-grade glioma patients treated by TMZ monotherapy. Because the MGMT promoter in normal tissue is generally unmethylated, methylated MGMT cases are susceptible to contamination by normal tissue. An advantage of qBGS is that it is easy to observe the state of contamination. qBGS also revealed intratumoral heterogeneity in the methylation of the MGMT promoter, which should be considered when using other methylation assays. Although qBGS is complicated and time-consuming, it is an important process for evaluating the methylation features of the MGMT promoter.

\section{Conclusions}

We constructed a novel diagnostic system to predict the prognosis of glioblastoma patients using information regarding the methylation status of the entire MGMT promoter region. A precise assessment of the methylation status of the MGMT promoter may improve the prediction of disease progression and assist in the choice of TMZ treatment.

\section{Additional files}

Additional file 1: Figure S1. Algorithm of quality assessment of bisulfite-treated genomic DNA. Figure S2. Schematic representation of leave-one-out cross-validation.

Additional file 2: Table S1. Table of regression coefficients of CpG sites based on PFS.

Additional file 3: Table S2. Table of regression coefficients of CpG sites based on OS.

Additional file 4: Agarose gel image of PCR product using FFPE genomic DNA.

\section{Abbreviations}

MGMT: O6-methylguanine-DNA methyltransferase; MSP: Methylation specific PCR, CpG, cytidine phosphate guanosine; PFS: Progression-free survival; OS: Overall survival; GB: Glioblastoma; TMZ: Temozolomide; qBGS: Quantitative bisulfite genome sequencing; DMSO: Dimethyl sulfoxide.

\section{Competing interests}

The authors declare that they have no competing interests. 


\section{Authors' contributions}

MK, AN, KN and KT performed the experiments in this study. MS, YK, YA, SM and KK supervised the research. MK and KK wrote this manuscript. All authors approved the final manuscript.

\section{Author details \\ ${ }^{1}$ Research Institute, Osaka Medical Center for Cancer and Cardiovascular Diseases, 1-3-3 Nakamichi, Higashinari-ku, Osaka, Japan. ${ }^{2}$ Department of Neurosurgery, Kyoto University Graduate School of Medicine, 54 Kawahara-cho, Shogoin, Sakyo-ku, Kyoto-shi, Kyoto 606-8507, Japan. ${ }^{3}$ Department of Neuro-Oncology/Neurosurgery, Saitama Medical University International Medical Center, 1397-1 Yamane, Hidaka, Saitama 350-1298, Japan.}

Received: 4 March 2014 Accepted: 27 August 2014

Published: 30 August 2014

\section{References}

1. Anderson E, Grant R, Lewis SC, Whittle IR: Randomized Phase III controlled trials of therapy in malignant glioma: where are we after 40 years? Br J Neurosurg 2008, 22(3):339-349.

2. Stupp R, Mason WP, van den Bent MJ, Weller M, Fisher B, Taphoorn MJ, Belanger K, Brandes AA, Marosi C, Bogdahn U, Curschmann J, Janzer RC, Ludwin SK, Gorlia T, Allgeier A, Lacombe D, Cairncross JG, Eisenhauer E, Mirimanoff RO: Radiotherapy plus concomitant and adjuvant temozolomide for glioblastoma. N Engl J Med 2005, 352(10):987-996.

3. Stupp R, Hegi ME, Mason WP, van den Bent MJ, Taphoorn MJ, Janzer RC, Ludwin SK, Allgeier A, Fisher B, Belanger K, Hau P, Brandes AA, Gijtenbeek J, Marosi C, Vecht CJ, Mokhtari K, Wesseling P, Villa S, Eisenhauer E, Gorlia T, Weller M, Lacombe D, Cairncross JG, Mirimanoff RO: Effects of radiotherapy with concomitant and adjuvant temozolomide versus radiotherapy alone on survival in glioblastoma in a randomised phase III study: 5-year analysis of the EORTC-NCIC trial. Lancet Oncol 2009, 10(5):459-466.

4. Chinot OL, Wick W, Saran F, Mason WP, Henriksson R, Nishikawa R, Zeaiter AH, Moore N, Das A, Cloughesy TF: AVAglio: a phase III trial of bevacizumab added to standard radiotherapy and temozolomide in patients with newly diagnosed glioblastoma. J Clin Oncol 2011, 29(suppl):abstr TPS136

5. Friedman HS, Prados MD, Wen PY, Mikkelsen T, Schiff D, Abrey LE, Yung WK, Paleologos N, Nicholas MK, Jensen R, Vredenburgh J, Huang J, Zheng M, Cloughesy T: Bevacizumab alone and in combination with irinotecan in recurrent glioblastoma. J Clin Oncol 2009, 27(28):4733-4740.

6. Gilbert MR, Dignam J, Won M, Blumenthal DT, Vogelbaum MA, Aldape KD, Colman H, Chakravarti A, Jeraj R, Armstrong TS, Wefel JS, Brown PD, Jaeckle KA, Schiff D, Atkins JN, Brachman D, Werner-Wasik M, Komaki R, Sulman EP, Mehta MP: RTOG 0825: Phase III double-blind placebo-controlled trial evaluating bevacizumab (Bev) in patients (Pts) with newly diagnosed glioblastoma (GBM). J Clin Oncol 2013, 31 (supp):abstr 1.

7. Drablos F, Feyzi E, Aas PA, Vaagbo CB, Kavli B, Bratlie MS, Pena-Diaz J, Otterlei M, Slupphaug G, Krokan HE: Alkylation damage in DNA and RNA-repair mechanisms and medical significance. DNA Repair (Amst) 2004, 3(11):1389-1407.

8. Gerson SL: MGMT: its role in cancer aetiology and cancer therapeutics. Nat Rev Cancer 2004, 4(4):296-307.

9. Kaina B, Christmann M, Naumann S, Roos WP: MGMT: key node in the battle against genotoxicity, carcinogenicity and apoptosis induced by alkylating agents. DNA Repair (Amst) 2007, 6(8):1079-1099.

10. Nagarajan RP, Costello JF: Epigenetic mechanisms in glioblastoma multiforme. Semin Cancer Biol 2009, 19(3):188-197.

11. Everhard S, Tost J, El Abdalaoui H, Criniere E, Busato F, Marie Y, Gut IG, Sanson M, Mokhtari K, Laigle-Donadey F, Hoang-Xuan K, Delattre JY, Thillet $\mathrm{J}$ : Identification of regions correlating MGMT promoter methylation and gene expression in glioblastomas. Neuro Oncol 2009, 11(4):348-356.

12. Gerson SL: Clinical relevance of MGMT in the treatment of cancer. J Clin Oncol 2002, 20(9):2388-2399.

13. Verbeek B, Southgate TD, Gilham DE, Margison GP: O6-Methylguanine-DNA methyltransferase inactivation and chemotherapy. Br Med Bull 2008, 85:17-33.

14. Esteller M, Garcia-Foncillas J, Andion E, Goodman SN, Hidalgo OF, Vanaclocha V, Baylin SB, Herman JG: Inactivation of the DNA-repair gene MGMT and the clinical response of gliomas to alkylating agents. N Engl I Med 2000, 343(19):1350-1354

15. Gorlia T, van den Bent MJ, Hegi ME, Mirimanoff RO, Weller M, Cairncross JG, Eisenhauer E, Belanger K, Brandes AA, Allgeier A, Lacombe D, Stupp R: Nomograms for predicting survival of patients with newly diagnosed glioblastoma: prognostic factor analysis of EORTC and NCIC trial 26981-22981/CE.3. Lancet Oncol 2008, 9(1):29-38.

16. Hegi ME, Diserens AC, Godard S, Dietrich PY, Regli L, Ostermann S, Otten P, Van Melle G, de Tribolet N, Stupp R: Clinical trial substantiates the predictive value of 0-6-methylguanine-DNA methyltransferase promoter methylation in glioblastoma patients treated with temozolomide. Clin Cancer Res 2004, 10(6):1871-1874.

17. Hegi ME, Diserens AC, Gorlia T, Hamou MF, de Tribolet N, Weller M, Kros JM, Hainfellner JA, Mason W, Mariani L, Bromberg JE, Hau P, Mirimanoff RO, Cairncross JG, Janzer RC, Stupp R: MGMT gene silencing and benefit from temozolomide in glioblastoma. N Engl J Med 2005, 352(10):997-1003.

18. Hegi ME, Liu L, Herman JG, Stupp R, Wick W, Weller M, Mehta MP, Gilbert MR: Correlation of O6-methylguanine methyltransferase (MGMT) promoter methylation with clinical outcomes in glioblastoma and clinical strategies to modulate MGMT activity. J Clin Oncol 2008, 26(25):4189-4199.

19. Gallego Perez-Larraya J, Ducray F, Chinot O, Catry-Thomas I, Taillandier L, Guillamo JS, Campello C, Monjour A, Cartalat-Carel S, Barrie M, Huchet A, Beauchesne P, Matta M, Mokhtari K, Tanguy ML, Honnorat J, Delattre JY: Temozolomide in elderly patients with newly diagnosed glioblastoma and poor performance status: an ANOCEF phase II trial. J Clin Oncol 2011, 29(22):3050-3055.

20. Taal W, Dubbink HJ, Zonnenberg CB, Zonnenberg BA, Postma TJ, Gijtenbeek JM, Boogerd W, Groenendijk FH, Kros JM, Kouwenhoven MC, van Marion R, van Heuvel I, van der Holt B, Bromberg JE, Sillevis Smitt PA, Dinjens WN, van den Bent MJ: First-line temozolomide chemotherapy in progressive low-grade astrocytomas after radiotherapy: molecular characteristics in relation to response. Neuro Oncol 2011, 13(2):235-241.

21. Malmstrom A, Gronberg BH, Marosi C, Stupp R, Frappaz D, Schultz H, Abacioglu U, Tavelin B, Lhermitte B, Hegi ME, Rosell J, Henriksson R: Temozolomide versus standard 6-week radiotherapy versus hypofractionated radiotherapy in patients older than 60 years with glioblastoma: the Nordic randomised, phase 3 trial. Lancet Oncol 2012, 13(9):916-926.

22. Wick W, Platten M, Meisner C, Felsberg J, Tabatabai G, Simon M, Nikkhah G, Papsdorf K, Steinbach JP, Sabel M, Combs SE, Vesper J, Braun C, Meixensberger J, Ketter R, Mayer-Steinacker R, Reifenberger G, Weller M: Temozolomide chemotherapy alone versus radiotherapy alone for malignant astrocytoma in the elderly: the NOA-08 randomised, phase 3 trial. Lancet Oncol 2012, 13(7):707-715.

23. Parkinson JF, Wheeler HR, Clarkson A, McKenzie CA, Biggs MT, Little NS, Cook RJ, Messina M, Robinson BG, McDonald KL: Variation of O(6)methylguanine-DNA methyltransferase (MGMT) promoter methylation in serial samples in glioblastoma. J Neurooncol 2008, 87(1):71-78.

24. Rand K, Qu W, Ho T, Clark SJ, Molloy P: Conversion-specific detection of DNA methylation using real-time polymerase chain reaction (ConLight-MSP) to avoid false positives. Methods 2002, 27(2):114-120.

25. Karayan-Tapon L, Quillien V, Guilhot J, Wager M, Fromont G, Saikali S, Etcheverry A, Hamlat A, Loussouarn D, Campion L, Campone M, Vallette FM, Gratas-Rabbia-Re C: Prognostic value of O6-methylguanine-DNA methyltransferase status in glioblastoma patients, assessed by five different methods. J Neurooncol 2010, 97(3):311-322.

26. Mikeska T, Bock C, El-Maarri O, Hubner A, Ehrentraut D, Schramm J, Felsberg J, Kahl P, Buttner R, Pietsch T, Waha A: Optimization of quantitative MGMT promoter methylation analysis using pyrosequencing and combined bisulfite restriction analysis. J Mol Diagn 2007, 9(3):368-381.

27. Aoki T, Takahashi JA, Ueba T, Oya N, Hiraoka M, Matsui K, Fukui T, Nakashima Y, Ishikawa M, Hashimoto N: Phase II study of nimustine, carboplatin, vincristine, and interferon-beta with radiotherapy for glioblastoma multiforme: experience of the Kyoto Neuro-Oncology Group. J Neurosurg 2006, 105(3):385-391.

28. Shirahata M, Iwao-Koizumi K, Saito S, Ueno N, Oda M, Hashimoto N, Takahashi JA, Kato K: Gene expression-based molecular diagnostic system for malignant gliomas is superior to histological diagnosis. Clin Cancer Res 2007, 13(24):7341-7356.

29. Shirahata M, Oba S, Iwao-Koizumi K, Saito S, Ueno N, Oda M, Hashimoto N, Ishii S, Takahashi JA, Kato K: Using gene expression profiling to identify a prognostic molecular spectrum in gliomas. Cancer Sci 2009, 100(1):165-172. 
30. Reesink-Peters N, Wisman GB, Jeronimo C, Tokumaru CY, Cohen Y, Dong SM, Klip HG, Buikema HJ, Suurmeijer AJ, Hollema H, Boezen HM, Sidransky $D$, van der Zee AG: Detecting cervical cancer by quantitative promoter hypermethylation assay on cervical scrapings: a feasibility study. Mol Cancer Res 2004, 2(5):289-295.

31. Esteller M, Hamilton SR, Burger PC, Baylin SB, Herman JG: Inactivation of the DNA repair gene O6-methylguanine-DNA methyltransferase by promoter hypermethylation is a common event in primary human neoplasia. Cancer Res 1999, 59(4):793-797.

32. Li H, Durbin R: Fast and accurate short read alignment with Burrows-Wheeler transform. Bioinformatics 2009, 25(14):1754-1760.

33. Li H, Handsaker B, Wysoker A, Fennell T, Ruan J, Homer N, Marth G, Abecasis G, Durbin R: The Sequence Alignment/Map format and SAMtools. Bioinformatics 2009, 25(16):2078-2079.

34. Shah N, Lin B, Sibenaller Z, Ryken T, Lee H, Yoon JG, Rostad S, Foltz G: Comprehensive analysis of MGMT promoter methylation: correlation with MGMT expression and clinical response in GBM. PLoS One 2011, 6(1):e16146.

35. van Nifterik KA, van den Berg J, van der Meide WF, Ameziane N, Wedekind LE, Steenbergen RD, Leenstra S, Lafleur MV, Slotman BJ, Stalpers L, Sminia P: Absence of the MGMT protein as well as methylation of the MGMT promoter predict the sensitivity for temozolomide. Br J Cancer 2010, 103(1):29-35.

36. Gerstner ER, Yip S, Wang DL, Louis DN, lafrate AJ, Batchelor TT: Mgmt methylation is a prognostic biomarker in elderly patients with newly diagnosed glioblastoma. Neurology 2009, 73(18):1509-1510.

37. Reifenberger $G$, Hentschel B, Felsberg J, Schackert G, Simon M, Schnell O, Westphal M, Wick W, Pietsch T, Loeffler M, Weller M: Predictive impact of MGMT promoter methylation in glioblastoma of the elderly. Int J Cancer 2012, 131(6):1342-1350.

38. McDonald KL, Rapkins RW, Olivier J, Zhao L, Nozue K, Lu D, Tiwari S, Kuroiwa-Trzmielina J, Brewer J, Wheeler HR, Hitchins MP: The T genotype of the MGMT C > T (rs16906252) enhancer single-nucleotide polymorphism (SNP) is associated with promoter methylation and longer survival in glioblastoma patients. Eur J Cancer 2013, 49(2):360-368.

39. Vlassenbroeck I, Califice S, Diserens AC, Migliavacca E, Straub J, Di Stefano I, Moreau F, Hamou MF, Renard I, Delorenzi M, Flamion B, DiGuiseppi J, Bierau $K$, Hegi ME: Validation of real-time methylation-specific PCR to determine O6-methylguanine-DNA methyltransferase gene promoter methylation in glioma. J Mol Diagn 2008, 10(4):332-337.

40. Hattermann K, Mehdorn HM, Mentlein R, Schultka S, Held-Feindt J: A methylation-specific and SYBR-green-based quantitative polymerase chain reaction technique for 06-methylguanine DNA methyltransferase promoter methylation analysis. Anal Biochem 2008, 377(1):62-71.

41. Metellus P, Coulibaly B, Nanni I, Fina F, Eudes N, Giorgi R, Barrie M, Chinot O, Fuentes S, Dufour H, Ouafik L, Figarella-Branger D: Prognostic impact of 06-methylguanine-DNA methyltransferase silencing in patients with recurrent glioblastoma multiforme who undergo surgery and carmustine wafer implantation: a prospective patient cohort. Cancer 2009 115(20):4783-4794

42. Dunn J, Baborie A, Alam F, Joyce K, Moxham M, Sibson R, Crooks D, Husband D, Shenoy A, Brodbelt A, Wong H, Liloglou T, Haylock B, Walker C: Extent of MGMT promoter methylation correlates with outcome in glioblastomas given temozolomide and radiotherapy. Br J Cancer 2009, 101(1):124-131.

43. Motomura K, Natsume A, Kishida Y, Higashi H, Kondo $Y$, Nakasu Y, Abe T, Namba H, Wakai K, Wakabayashi T: Benefits of interferon-beta and temozolomide combination therapy for newly diagnosed primary glioblastoma with the unmethylated MGMT promoter: A multicenter study. Cancer 2011, 117(8):1721-1730.

44. Bady P, Sciuscio D, Diserens AC, Bloch J, van den Bent MJ, Marosi C, Dietrich PY, Weller M, Mariani L, Heppner FL, McDonald DR, Lacombe D, Stupp R, Delorenzi M, Hegi ME: MGMT methylation analysis of glioblastoma on the Infinium methylation BeadChip identifies two distinct $\mathrm{CpG}$ regions associated with gene silencing and outcome, yielding a prediction model for comparisons across datasets, tumor grades, and CIMP-status. Acta Neuropathol 2012, 124(4):547-560.

45. Yan H, Parsons DW, Jin G, McLendon R, Rasheed BA, Yuan W, Kos I, Batinic-Haberle I, Jones S, Riggins GJ, Friedman H, Friedman A, Reardon D, Herndon J, Kinzler KW, Velculescu VE, Vogelstein B, Bigner DD: IDH1 and IDH2 mutations in gliomas. N Engl J Med 2009, 360(8):765-773.
46. Noushmehr H, Weisenberger DJ, Diefes K, Phillips HS, Pujara K, Berman BP, Pan F, Pelloski CE, Sulman EP, Bhat KP, Verhaak RG, Hoadley KA, Hayes DN, Perou CM, Schmidt HK, Ding L, Wilson RK, Van Den Berg D, Shen H, Bengtsson H, Neuvial P, Cope LM, Buckley J, Herman JG, Baylin SB, Laird PW, Aldape $\mathrm{K}$ : Identification of a CpG island methylator phenotype that defines a distinct subgroup of glioma. Cancer Cell 2010, 17(5):510-522.

47. van den Bent MJ, Gravendeel LA, Gorlia T, Kros JM, Lapre L, Wesseling P, Teepen $J$, Idbaih A, Sanson M, Smitt PA, French PJ: A hypermethylated phenotype is a better predictor of survival than MGMT methylation in anaplastic oligodendroglial brain tumors: a report from EORTC study 26951. Clin Cancer Res 2011, 17(22):7148-7155.

48. Hoang-Xuan K, Capelle L, Kujas M, Taillibert S, Duffau H, Lejeune J, Polivka M, Criniere E, Marie Y, Mokhtari K, Carpentier AF, Laigle F, Simon JM, Cornu P, Broet P, Sanson M, Delattre JY: Temozolomide as initial treatment for adults with low-grade oligodendrogliomas or oligoastrocytomas and correlation with chromosome 1p deletions. J Clin Oncol 2004, 22(15):3133-3138.

doi:10.1186/1471-2407-14-641

Cite this article as: Kanemoto et al:: Prognostic prediction of glioblastoma by quantitative assessment of the methylation status of the entire MGMT promoter region. BMC Cancer 2014 14:641.

\section{Submit your next manuscript to BioMed Central and take full advantage of:}

- Convenient online submission

- Thorough peer review

- No space constraints or color figure charges

- Immediate publication on acceptance

- Inclusion in PubMed, CAS, Scopus and Google Scholar

- Research which is freely available for redistribution

Submit your manuscript at www.biomedcentral.com/submit
C) Biomed Central 